\title{
Affinity and Efficacy Studies of Tetrahydrocannabinolic Acid A at Cannabinoid Receptor Types One and Two
}

\author{
John M. McPartland, ${ }^{1,2, *}$ Christa MacDonald, ${ }^{3}$ Michelle Young, ${ }^{3}$ Phillip S. Grant, ${ }^{4}$ Daniel P. Furkert, ${ }^{4}$ and Michelle Glass ${ }^{3}$
}

\begin{abstract}
Introduction: Cannabis biosynthesizes $\Delta^{9}$-tetrahydrocannabinolic acid (THCA-A), which decarboxylates into $\Delta^{9}$-tetrahydrocannabinol (THC). There is growing interest in the therapeutic use of THCA-A, but its clinical application may be hampered by instability. THCA-A lacks cannabimimetic effects; we hypothesize that it has little binding affinity at cannabinoid receptor $1\left(\mathrm{CB}_{1}\right)$.

Materials and Methods: Purity of certified reference standards were tested with high performance liquid chromatography (HPLC). Binding affinity of THCA-A and THC at human (h) $C_{1}$ and $h C B_{2}$ was measured in competition binding assays, using transfected $H E K$ cells and $\left.{ }^{3} \mathrm{H}\right] \mathrm{CP} 55,940$. Efficacy at $h \mathrm{hCB}_{1}$ and $\mathrm{hCB_{2 }}$ was measured in a cyclic adenosine monophosphase (CAMP) assay, using a Bioluminescence Resonance Energy Transfer (BRET) biosensor. Results: The THCA-A reagent contained 2\% THC. THCA-A displayed small but measurable binding at both $\mathrm{hCB}_{1}$ and $\mathrm{hCB}_{2}$, equating to approximate $\mathrm{K}_{\mathrm{i}}$ values of $3.1 \mu \mathrm{M}$ and $12.5 \mu \mathrm{M}$, respectively. THC showed 62 -fold greater affinity at $h \mathrm{hB}_{1}$ and 125 -fold greater affinity at $h \mathrm{hCB}_{2}$. In efficacy tests, THCA-A (10 $\left.\mu \mathrm{M}\right)$ slightly inhibited forskolinstimulated $C A M P$ at $h C B_{1}$, suggestive of weak agonist activity, and no measurable efficacy at $h C_{2}$.

Discussion: The presence of THC in our THCA-A certified standard agrees with decarboxylation kinetics (literature reviewed herein), which indicate contamination with THC is nearly unavoidable. THCA-A binding at $10 \mu \mathrm{M}$ approximated THC binding at 200nM. We therefore suspect some of our THCA-A binding curve was artifactfrom its inevitable decarboxylation into THC - and the binding affinity of THCA-A is even weaker than our estimated values. We conclude that THCA-A has little affinity or efficacy at $\mathrm{CB}_{1}$ or $\mathrm{CB}_{2}$.
\end{abstract}

Keywords: cannabinoid receptors; Cannabis; pharmacodynamics; pharmacology; phytocannabinoids; THCA

\section{Introduction}

Cannabis biosynthesizes cannabinoids as carboxylic acids. The carboxylic acid of $\Delta^{9}$-tetrahydrocannabinol (THC) is $\Delta^{9}$-tetrahydrocannabinolic acid (THCA). Two isomers of THCA have been discovered, 2-COOH-THC (THCA-A) and 4-COOH-THC (THCA-B) (Fig. 1). Cannabis primarily biosynthesizes THCA-A, ${ }^{1}$ and this isomer has been the focus of most pharmacological studies. Conversely, THCA-B has greater stability and crystalizes more readily than THCA-A, ${ }^{2}$ so THCA-B became the molecule for modeling studies of cannabinoid receptors. According to the canonical cannabinoid biosynthesis pathway, olivetolic acid is prenylated into cannabigerolic acid (CBGA) with its carboxylic acid in an "A" position. The allylic rearrangement yielding THCA-B begs a mechanism.

There is growing interest in the therapeutic use of THCA-A., ${ }^{3,4}$ The gray literature is immense: a simple

\footnotetext{
${ }^{1} \mathrm{GW}$ Pharmaceuticals, Salisbury, United Kingdom.

${ }^{2}$ Department of Family Medicine, University of Vermont, Burlington, Vermont.

${ }^{3}$ Department of Pharmacology \& Clinical Pharmacology, University of Auckland, Auckland, New Zealand.

${ }^{4}$ School of Chemical Sciences, University of Auckland, Auckland, New Zealand.

*Address correspondence to: John M. McPartland, DO, MS, 53 Washington Street Ext., Middlebury, VT 05753, E-mail: mcpruitt@myfairpoint.net
}

(c) John M. McPartland et al. 2017; Published by Mary Ann Liebert, Inc. This is an Open Access article distributed under the terms of the Creative Commons Attribution License, which permits unrestricted use, distribution, and reproduction in any medium, provided the original work is properly cited. Mary Ann Liebert, Inc. offers reprint services for those who want to order professionally produced copies of articles published under the Creative Commons Attribution (CC BY) license. To obtain a price quote, email Reprints@liebertpub.com. Please include the articlés title or DOI, quantity, and delivery destination in your email. 

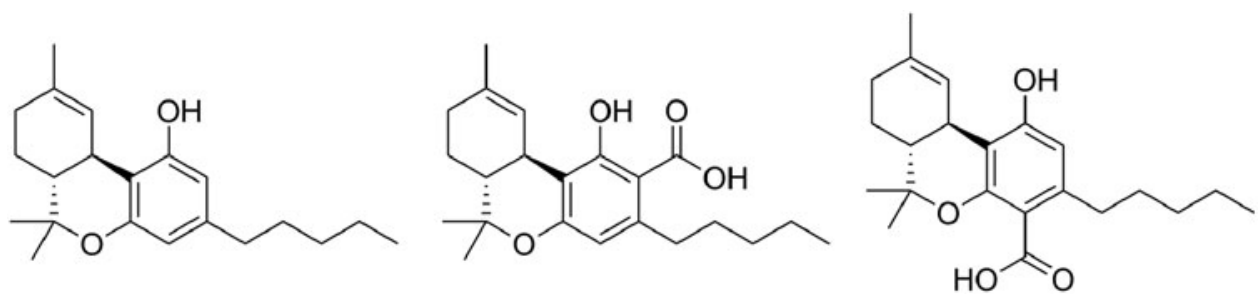

FIG. 1. Chemical structures of THC (left), THCA-A (center), and THCA-B (right). THC, $\Delta^{9}$-tetrahydrocannabinol; THCA-A, $\Delta^{9}$-tetrahydrocannabinolic acid A; THCA-B, 4-COOH-THC.

Google search of "tetrahydrocannabinolic acid" plus "medical" returns 14,000 hits. The clinical application of THCA-A, however, is complicated by thermal instability - it readily decarboxylates into THC. This happens with heating (smoking and baking), as well as storage, at room temperature.

Studies on the "shelf life" of THCA-A are worth reviewing, for clinical purposes, as well as pharmacological research. Ethanol and olive oil extract approximately the same THCA-A/THC ratio from plant material, ${ }^{5,6}$ but THCA-A stability is greater in olive oil (78\% of THCAA remained after 10 days at $25^{\circ}$ ) than ethanol (only $33 \%$ remained). ${ }^{6}$ THCA-A is even less stable in hydroethanolic solvents. ${ }^{7}$ Other stability studies tested solvents used for laboratory reagents-methanol, chloroform, petroleum ether, and $n$-hexane. ${ }^{8,9}$ Decarboxylation rates depended upon temperature, with considerable losses at room temperature, and exposure to light accelerated the process. When stored for a month at refrigerator temperature $\left(4^{\circ} \mathrm{C}\right)$, THCA-A decreased to between $91 \%$ (in methanol) and $68 \%$ (in chloroform) of initial levels. Losses still occurred at freezer temperature $\left(-18^{\circ} \mathrm{C}\right){ }^{8}$

Hazekamp et al. ${ }^{10}$ demonstrated short-term stability in "cannabis tea." They added quantified amounts of THCA-A and THC to boiled water. After $15 \mathrm{~min}$ of simmering above $55^{\circ} \mathrm{C}$, they recovered $63 \%$ of THCA-A and only $17 \%$ of THC. However, THCA-A loss was substantial in cannabis tea stored at $4^{\circ} \mathrm{C}$-decreasing to $71 \%$ of initial levels after 1 day. THCA-A rapidly decarboxylates if water is boiled after cannabis is added to it. ${ }^{11}$

Studies suggest that THCA-A may be more stable in herbal cannabis, where it is "hermetically sealed" within glandular trichomes, along with terpenoids which serve as protective antioxidants.

Studies suggest that THCA-A may be more stable in herbal cannabis, where it is "hermetically sealed" within glandular trichomes, whose gland heads contain up to
$10 \%$ terpenoids. ${ }^{12}$ Terpenoids are potent antioxidants, ${ }^{13}$ protect living plants from thermal and oxidative stress, ${ }^{14}$ and likely inhibit the oxidative decarboxylation of THCA-A. Decarboxylation kinetics have been measured by heating herbal cannabis in undescribed conditions, ${ }^{15}$ in a nitrogen atmosphere, ${ }^{16}$ in sealed glass bottles, ${ }^{17}$ or cardboard boxes. ${ }^{18}$ Collectively, these studies showed that THCA-A decarboxylated within minutes at temperatures above $80^{\circ} \mathrm{C}$. At room temperature in glass bottles with limited exposure to light, THCA-A dropped to $80 \%$ of initial levels after 25 months. At refrigerator $\left(4^{\circ} \mathrm{C}\right)$ temperatures, $94.7 \%$ of THCA-A was still present.

THCA-A "shelf life" may be extended in hashish, where gland heads are mechanically detached and compacted to minimize exposure to light and oxygen. ${ }^{8,11,19}$ Baker et al. ${ }^{20}$ measured THCA and THC in seized materials, all approximately the same age. The THCA/THC ratio in hashish (mean 3.08) was greater than herbal material (mean 1.96).

The growing clinical interest in THCA-A is due, in part, to its perceived lack of cannabimimetic effects. ${ }^{15,21,22}$ This may be due to a lack of binding affinity at cannabinoid receptor type one $\left(\mathrm{CB}_{1}\right)$. Affinity studies of THCA-A at $\mathrm{CB}_{1}$ report disparate results-equal to $\mathrm{THC}^{23}$ or 25 fold weaker than $\mathrm{THC}^{24}$ or lacking affinity. ${ }^{25,26}$ As we elaborate in the Discussion section, this incongruence is best explained by THCA-A contaminated by THC. Similarly, Edery et al. ${ }^{21}$ demonstrated very weak psychoactivity in rhesus monkeys, which they discounted as some THCA-A decarboxylating into THC during the course of the experiment.

In this current study, we measured the affinity of THCA-A at $\mathrm{CB}_{1}$, as well as cannabinoid receptor subtype two $\left(\mathrm{CB}_{2}\right)$, as well as the efficacy of THCA-A at $\mathrm{CB}_{1}$ and $\mathrm{CB}_{2}$. We used a certified reference standard (meeting ISO17025 guidelines), but high performance liquid chromatography (HPLC) revealed that our THCA-A reference standard was contaminated by $2 \%$ THC. In this 
study we show that the only binding or efficacy detected for THCA-A is consistent with the level of THC contamination contained in the sample.

\section{Methods}

THCA-A was purchased from Cayman Chemical (lot no. 0466688) as a $1 \mathrm{mg} / \mathrm{mL}$ solution in acetonitrile. THC was purchased from THC Pharm GmbH (lot no. S12-003, delivered as a solid resin in a glass syringe) and dissolved at $31.6 \mathrm{mM}$ in nitrogen-purged absolute ethanol. Materials were stored at $-20^{\circ} \mathrm{C}$ (THCA-A) or $-80^{\circ} \mathrm{C}$ (THC) before experimentation. Purity was assessed by reverse-phase HPLC using a Phenomenex ${ }^{\mathrm{TM}} \mathrm{C}_{18}$ Gemini column $(5 \mu \mathrm{m}, 4.60 \times 250 \mathrm{~mm})$ on a Thermo Scientific UltiMate 3000 HPLC. A linear gradient of $65-100 \%$ $\mathrm{MeOH}$ (ca. $1 \% / \mathrm{min}$ ) in $\mathrm{H}_{2} \mathrm{O}$ with $0.1 \%$ formic acid was used.

Competition binding assays ${ }^{27}$ for $\mathrm{hCB}_{1}$ and $\mathrm{hCB}_{2}$ were performed by incubating either THC or THCAA with membranes from HEK (human embryonic kidney) 293 cells transfected with either $\mathrm{hCB}_{1}$ or $\mathrm{hCB}_{2}$ receptors as previously described. ${ }^{28,29}$ Transfected HEK 293 cells were grown to $90-100 \%$ confluence in $175 \mathrm{~cm}^{2}$ flasks and harvested in ice-cold phosphate buffered saline (PBS) with $5 \mathrm{mM}$ EDTA. Cells were centrifuged at $200 \times g$ for $10 \mathrm{~min}$ and frozen at $-80^{\circ} \mathrm{C}$ until required. Cell pellets were thawed with Tris-sucrose buffer $(50 \mathrm{mM}$ Tris- $\mathrm{HCl}, \mathrm{pH} 7.4,200 \mathrm{mM}$ sucrose, $5 \mathrm{mM}$ $\mathrm{MgCl}_{2}, 2.5 \mathrm{mM}$ EDTA) and homogenized with a glass homogenizer. The homogenate was centrifuged at $1000 \times g$ for $10 \mathrm{~min}$ at $4^{\circ} \mathrm{C}$ and the pellet discarded. The supernatant was then centrifuged at $27,000 \times g$ for $30 \mathrm{~min}$ at $4^{\circ} \mathrm{C}$. The final pellet was resuspended in a minimal volume of Tris-sucrose buffer and aliquoted to avoid repeated freeze-thaw cycles.

Protein concentration was determined using the DC Protein Assay Kit (Bio-Rad, Hercules, CA) following the manufacturers' protocol. Membranes $(10 \mu \mathrm{g} /$ point for $\mathrm{CB}_{1}$ and $5 \mu \mathrm{g} /$ point for $\mathrm{CB}_{2}$ ) were resuspended in binding buffer (50 mM HEPES, $1 \mathrm{mM} \mathrm{MgCl}_{2}, 1 \mathrm{mM}$ $\mathrm{CaCl}_{2}, 0.2 \%[\mathrm{w} / \mathrm{v}$ ] bovine serum albumin [BSA; ICP Bio], $\mathrm{pH}$ 7.4) and incubated with $\left[{ }^{3} \mathrm{H}\right]-\mathrm{CP} 55,940$ (2.5 nM; PerkinElmer, Waltham, MA; two different lots were used 175 and $150.2 \mathrm{Ci} \mathrm{mmol}^{-1}$ ) and a range of THC or THCA-A concentrations at $30^{\circ} \mathrm{C}$ for $60 \mathrm{~min}$. THC and THCA-A were diluted directly from stocks to $40 \mu \mathrm{M}$ in binding buffer supplemented with acetonitrile and ethanol, respectively, to match vehicle conditions with each compound. The compounds were then serially diluted in silanized vessels, maintaining ethanol and acetonitrile levels constant through the dilution series. These $4 \times$ dilution series were then added to a v-bottom 96-well plate with radioligand and cell membranes such that the final $1 \times$ concentration contained both $0.04 \%$ ethanol and $0.36 \%$ acetonitrile. These solvents were matched in the vehicle conditions.

GF/C Harvest Plates (PerkinElmer) were presoaked in $0.1 \%$ polyethylenimine and then washed with $200 \mu \mathrm{L}$ ice-cold wash buffer (50 mM HEPES pH 7.4 $500 \mathrm{mM} \mathrm{NaCl}, 0.1 \%$ BSA) before filtration of samples and then three additional $200 \mu \mathrm{L}$ washes in ice-cold wash buffer. Harvest plates were dried overnight at $24^{\circ} \mathrm{C}, 50 \mu \mathrm{L}$ of scintillation fluid (IRGASAFE PLUS; PerkinElmer) was added to each well, and plates were read 30 min later for 2 min per well in a MicroBeta TriLux (PerkinElmer).

Competition binding curves were fit by nonlinear regression using one site competition binding with GraphPad Prism 6.0. Dissociation constant in a competition binding assay $\left(\mathrm{K}_{\mathrm{i}}\right)$ was determined from half maximal inhibitory concentration $\left(\mathrm{IC}_{50}\right)$ using previously established $\mathrm{K}_{\mathrm{d}}$ of $2.5 \mathrm{nM}\left(\mathrm{CB}_{1}\right)$ or $3 \mathrm{nM}\left(\mathrm{CB}_{2}\right)$, respectively, (unpublished data). Binding experiments for $\mathrm{CB}_{1}$ and $\mathrm{CB}_{2}$ were performed five times in triplicate. $\mathrm{pKi}$ values are expressed as mean \pm standard error of the mean (SEM). For THCA-A full binding curves could not be established (because it failed to fully displace $\left[{ }^{3} \mathrm{H}\right]-\mathrm{CP} 55,940$ at concentrations up to $10 \mu \mathrm{M}$ ); therefore, we estimated percentage displacement at $10 \mu \mathrm{M}$. This was converted to an approximate $\mathrm{IC}_{50}$ by assuming a hill slope of 1 and utilizing the following equation: $I C 50=10 \mu M /\left(\frac{\% \text { displacement }}{100-\% \text { displacement }}\right)$ and then to approximate $\mathrm{K}_{\mathrm{i}}$ using the Cheng-Prusoff equation: $K i=I C 50 /\left(1+\frac{[L]}{K L}\right)$

Efficacy at $\mathrm{hCB}_{1}$ and $\mathrm{hCB}_{2}$ was investigated in a cyclic adenosine monophosphase (cAMP) assay, to determine if THCA-A could inhibit forskolin-stimulated cAMP (i.e., act as an agonist) or prevent the inhibition produced by $\mathrm{EC}_{90}$ concentrations of CP55,940 (i.e., act as an antagonist). Cellular cAMP levels were measured as previously described. ${ }^{28}$ Briefly, the pcDNA3L-HisCAMYEL plasmid (ATCC, Manassas, VA) was transfected into HEK 293-hCB 1 or $\mathrm{hCB}_{2}$ cells using linear polyethylenimine (molecular weight $25 \mathrm{kDa}$; Polysciences, Warrington, PA). After $24 \mathrm{~h}$ transfection cells were 
replated in poly-D-lysine $\left(0.05 \mathrm{mg} \mathrm{mL}^{-1}\right.$ in PBS; SigmaAldrich, St Louis, MO) coated 96 Well Solid White Flat Bottom Polystyrene TC-Treated Microplates (Corning) at a density of 55,000-80,000 cells per well. After $24 \mathrm{~h}$, cells were serum-starved in Hank's balanced salt solution (HBSS) containing $1 \mathrm{mg} \mathrm{mL}^{-1} \mathrm{BSA}$, pH 7.4 for $30 \mathrm{~min}$ before assay. Five minutes before the addition of drug or vehicle dissolved in HBSS plus $1 \mathrm{mg} \mathrm{mL}^{-1}$ BSA cells were treated with $5 \mu \mathrm{M}$ Coelenterazine-h (Nanolight Technology). Emission signals were detected simultaneously at 460/25 nM (RLuc) and 560/25 nM (YFP), immediately following drug addition, with a LUMIstar plate reader (BMG) at $37^{\circ} \mathrm{C}$. Raw data are presented as an inverse bioluminescence resonance energy transfer (BRET) ratio of emission at $460 / 535 \mathrm{nM}$, so that an increase in ratio correlates with an increase in cAMP production. Area under the curve analysis was carried out using GraphPad Prism, and values normalized to forskolin (100\%) and vehicle (0\%). $t$-Tests (GraphPad Prism) were utilized to determine if THCA-A significantly altered the response in the presence or absence of CP55,940.

\section{Results}

HPLC revealed the presence of $2 \%$ THC $\left(\mathrm{THC}_{\mathrm{RT}}=18.2\right.$ $\mathrm{min}$ ) in the THCA-A sample (THCA- $\mathrm{A}_{\mathrm{RT}}=23.9 \mathrm{~min}$ ), established by correlation of retention time with an authentic sample of THC. The THC and THCA-A peaks were correlated to their respective molecular ions by electrospray ionization (ESI) mass spectrometry (THC $m / z=338.1,[\mathrm{M}+\mathrm{Na}]^{1+}$ requires 337.5 ; THCA-A $\mathrm{m} / z=$ 359.0, $[\mathrm{M}+\mathrm{H}]^{1+}$ requires 359.5$)$. Chromatograms of the two samples are illustrated in Figure 2.

To determine if THCA-A could bind to the orthosteric binding site of $\mathrm{hCB}_{1}$ or $\mathrm{hCB}_{2}$, competition displacement assays were carried out (Fig. 3). Full displacement could not be achieved with THCA-A concentrations up to $10 \mu \mathrm{M}$. At $10 \mu \mathrm{M}$ THCA-A produced a small but significant displacement at both $\mathrm{hCB}_{1}(62 \% \pm 3 \%)$ and $\mathrm{hCB}_{2}(40 \% \pm 8 \%)$. This level of displacement was insufficient to fully define competition binding curves, but would equate to approximate $\mathrm{pK}_{\mathrm{i}}$ 's of $5.5(3.1 \mu \mathrm{M})$ and $4.9(12.5 \mu \mathrm{M})$, respectively. For comparative purposes competition binding assays were carried out with THC. THC fully displaced $\left[{ }^{3} \mathrm{H}\right] \mathrm{CP} 55,940$ with mean $\mathrm{pK}_{\mathrm{i}}=7.3 \pm$ $0.03\left(\mathrm{hCB}_{1} ; 50 \mathrm{nM}\right)$ and $-7.0 \pm 0.04\left(\mathrm{hCB}_{2} ; 100 \mathrm{nM}\right)$.

To determine if THCA-A could activate or block cannabinoid receptors, cAMP assays were carried out using a BRET biosensor as previously described. ${ }^{28}$ As both cannabinoid receptors are predominantly guanine nucleotidebinding protein subunit $i\left(G_{i}\right)$ linked and therefore couple to the inhibition of cAMP, cAMP levels were increased with forskolin and then the ability of $10 \mu \mathrm{M}$ THCA-A to alter cAMP was investigated in the presence and absence of the cannabinoid agonist $\mathrm{CP} 55,940$ at approximate $\mathrm{EC}_{90}$ concentrations $\left(4 \mathrm{nM}\right.$ at $\mathrm{hCB}_{1}$ and $20 \mathrm{nM}$ at $\mathrm{hCB}_{2}$ ). For comparison inhibition of forskolin mediated cAMP by $10 \mu \mathrm{M}$ THC was also carried out. cAMP levels were measured for $9.9 \mathrm{~min}(595 \mathrm{sec})$, and then data were analyzed by an Area under the curve analysis, normalized to forskolin (100\% and vehicle $0 \%)$.

As shown in Figure 4, at $\mathrm{hCB}_{1} \mathrm{CP} 55,940$ inhibited forskolin stimulated cAMP to $50 \% \pm 3.5 \%$. In the presence of $10 \mu \mathrm{M}$ THCA-A this stimulation was partially but significantly reversed to $59 \% \pm 1.8 \%(p=0.0065$ by paired $t$-test, $n=5)$. On its own THCA-A produced a small but significant inhibition to $79 \% \pm 5 \%$ ( $t$-test compared to $100 \% p=0.015)$. At $\mathrm{hCB}_{2}, \mathrm{CP} 55,940$ inhibited to $53 \% \pm 6 \%$, which was unaltered in the presence of THCA-A $(55 \% \pm 7 \% p=0.6, n=6)$. Consistent with this, THCA-A alone produced no inhibition of forskolin mediated cAMP $(99 \% \pm 2 \%, p=0.64, n=6)$. As expected, THC $(10 \mu \mathrm{M})$ produced equivalent inhibition of cAMP to that produced by CP55,940, acting as an efficacious agonist in this assay.

\section{Discussion}

Although there is growing interest in THCA-A among clinicians, ${ }^{3,4}$ decarboxylation studies suggest that contamination with THC is nearly unavoidable..$^{5-11,15-20}$ The instability of THCA-A also hampers its pharmacological exploration. ${ }^{21}$ "How can anybody do an experiment if the compound likes to convert into something else just by sitting around, and the 'something else' has all kinds of activities?" (R. Mechoulam, personal communication, January 2017). Our study optimized in vitro stability by keeping THCA-A in acetonitrile. In vitro assays of THC can also be hampered by solubility issues. Our results with THC $\left(\mathrm{K}_{\mathrm{i}}=50 \mathrm{nM}\right.$ at $\mathrm{hCB}_{1}$ ) indicate that THC did not fall out of solution. Because THCA-A is more water soluble than THC, ${ }^{10}$ we concluded that our results with THCA-A were not due to solubility issues.

THCA-A's lack of psychoactivity makes it attractive in some circles. Moreno-Sanz ${ }^{30}$ hypothesized that lack of cannabimimetic effects is due to restricted access to the central nervous system (CNS). Others have explored the affinity and efficacy of THCA-A at cannabinoid receptors. Rosenthaler et al. ${ }^{23}$ determined a $\mathrm{K}_{\mathrm{i}}$ of $23.4 \mathrm{nM}$ for THCA-A at $\mathrm{hCB}_{1}$, nearly equivalent to their measure of $\mathrm{K}_{\mathrm{i}}$ of $35.6 \mathrm{nM}$ for THC. This is in agreement 

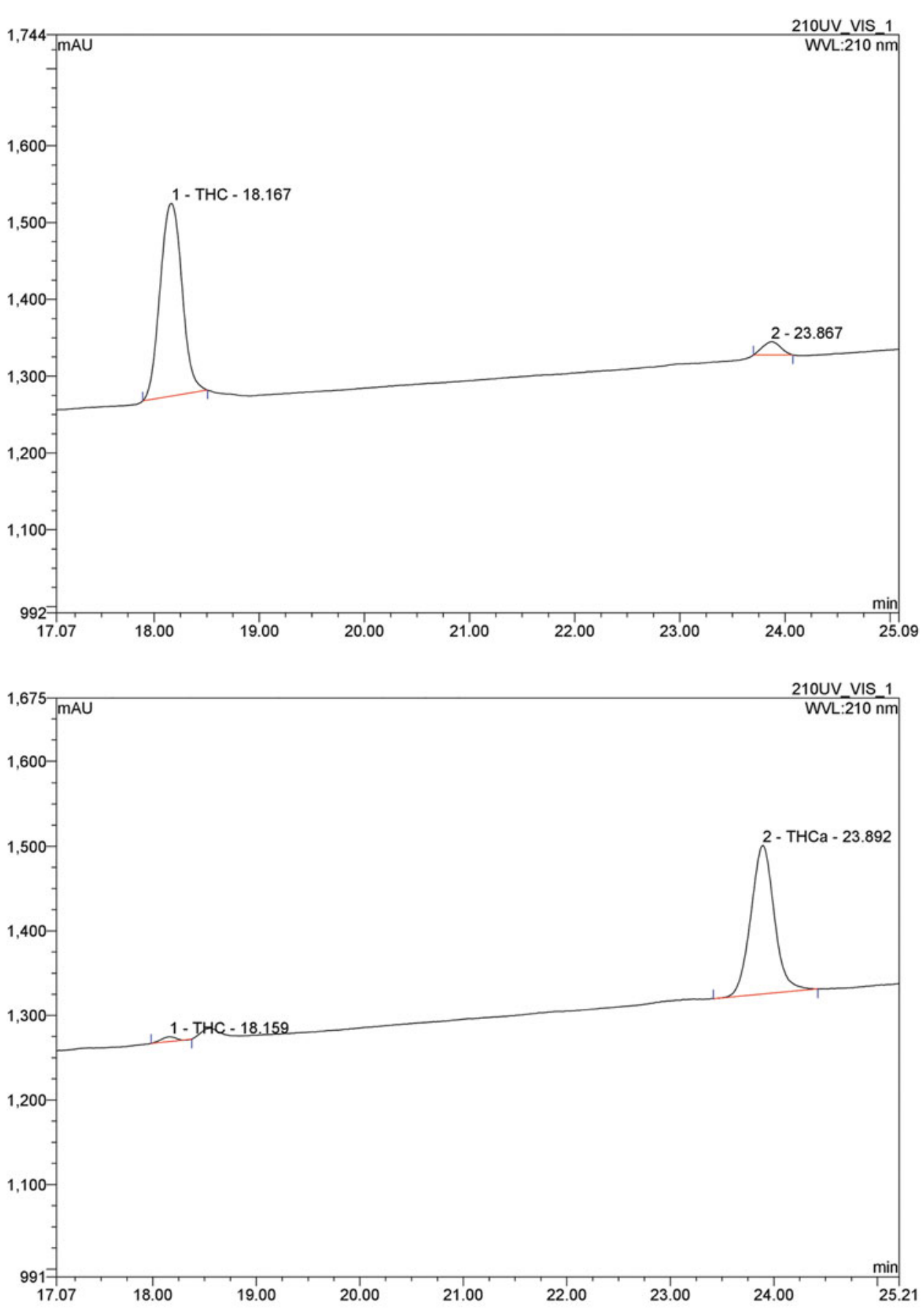

\begin{tabular}{|r|clrrr|}
\hline No. & $\begin{array}{c}\text { Ret.Time } \\
\text { min }\end{array}$ & \multicolumn{1}{c}{ Peak Name } & $\begin{array}{c}\text { Height } \\
\text { mAU }\end{array}$ & $\begin{array}{c}\text { Area } \\
\text { mAU*min }\end{array}$ & $\begin{array}{c}\text { Rel.Area } \\
\%\end{array}$ \\
\hline 1 & 18.16 & THC & 5.566 & 0.857 & 1.82 \\
2 & 23.89 & THCa & 175.861 & 46.178 & 98.18 \\
\hline Total: & & & 181.427 & 47.034 & 100.00 \\
\hline
\end{tabular}

FIG. 2. Analytical RP-HPLC of THCA-A sample (lower panel) and THC standard (upper panel); absorbance detected at $210 \mathrm{~nm}$. HPLC, high performance liquid chromatography. 

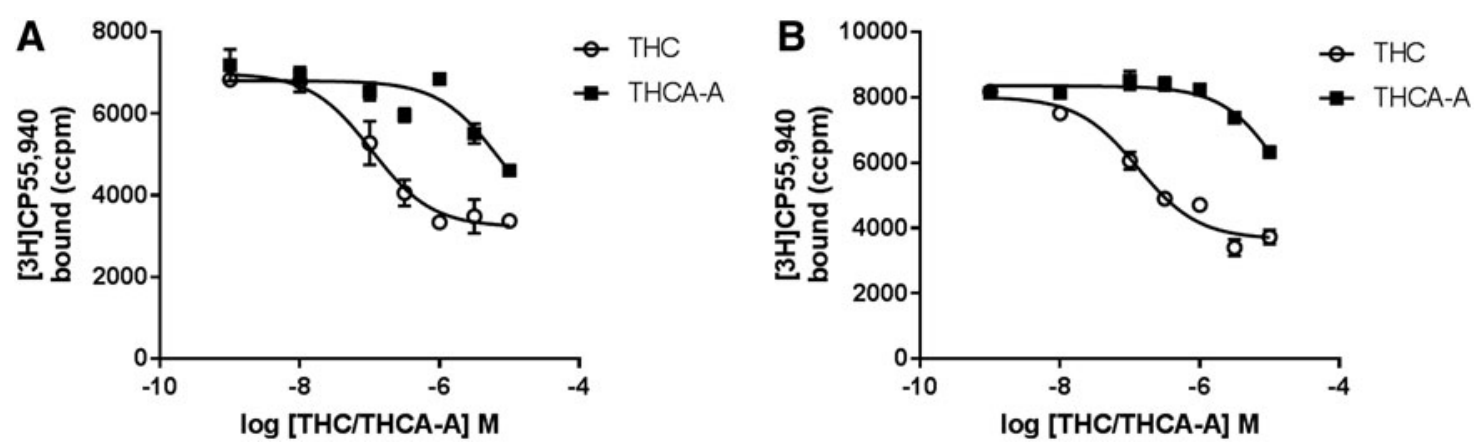

FIG. 3. Binding affinity of THCA-A and THC illustrated in competition binding curves against $\left[{ }^{3} \mathrm{H}\right] \mathrm{CP} 55,940$. $C B_{1}$ on the left $(A)$ and $C B_{2}$ on the right (B). Data are representative data from a single experiment and data points represent mean \pm SEM for triplicate data points. $\mathrm{CB}_{1}$, cannabinoid receptor subtype one; $\mathrm{CB}_{2}$, cannabinoid receptor subtype two; SEM, standard error of the mean.

with a meta-analysis of $\mathrm{THC}$ at $\mathrm{hCB}_{1}$, which reported a mean $\mathrm{K}_{\mathrm{i}}$ of $25.1 \pm 0.39 \mathrm{nM}$ ( $n=16$ studies). ${ }^{31}$

Verhoeckx et al. $^{24}$ determined a $\mathrm{K}_{\mathrm{i}}$ of $890 \mathrm{nM}$ for THCA-A at $\mathrm{hCB}_{1}$. They also determined a $\mathrm{K}_{\mathrm{i}}$ of $3.5 \mathrm{nM}$ for THC at $\mathrm{hCB}_{1}$, which is sevenfold greater than the meta-analytic mean. Applying this multiplier to their $\mathrm{K}_{\mathrm{i}}$ of THCA-A would produce a $\mathrm{K}_{\mathrm{i}}$ broadly consistent with our results. Ahmed et al. ${ }^{25}$ simply stated "no activity" for THCA-A at $\mathrm{CB}_{1}$, without a $\mathrm{K}_{\mathrm{i}}$ value. Husni et al. ${ }^{26}$ determined a $K_{i}$ of $1292 \mathrm{nM}$ for THCA-A at $\mathrm{CB}_{1}$. Although they illustrate an incorrect structure for THCA-A, their results do indeed apply to THCA-A (M. Radwan, personal communication, January 2017).

The reason for these disparate results cannot be easily explained. The methods used in these studies are compared in Table 1. Methodological details not supplied in original publications were obtained through personal communications (S. Rosenthaler, April 2015; K. Verhoeckx, April 2017; M. Radwan, January 2017). Affinity values among different studies may vary according to radioligand, $\mathrm{CB}$ species, and expression model, but these methodological factors rarely generate statistical differences. ${ }^{31}$ More likely, some THCA-A decarboxylated in these studies. The two studies that reported affinity ${ }^{23,24}$ did not authenticate the purity of their THCA-A reagents, whereas the two studies that reported no affinity ${ }^{25,26}$ authenticated THCA-A with HPLC and nuclear magnetic resonance (NMR) (authentication confirmed by M. Radwan, personal communication, January 2017).

THCA-A showed little affinity at $\mathrm{hCB}_{1}$ in our competition binding assays. On the basis of $60 \%$ displacement at $10 \mu \mathrm{M}$, a $\mathrm{K}_{\mathrm{i}}$ of $3 \mu \mathrm{M}$ can be estimated, making it broadly comparable to that of cannabidiol $\left(\mathrm{K}_{\mathrm{i}}=2.2 \mu \mathrm{M}^{31}\right)$ - a decidedly non-cannabimimetic ligand. At $\mathrm{hCB}_{2}$, THCA-A slightly displaced $\left[{ }^{3} \mathrm{H}\right] \mathrm{CP} 55,940$ in binding assays-less than that produced at $\mathrm{CB}_{1}$, reaching $40 \%$ displacement at $10 \mu \mathrm{M}$, consistent with an estimated $\mathrm{K}_{\mathrm{i}}$ of $12.5 \mu \mathrm{M}$. In comparison, THC showed 62 -fold greater affinity at $\mathrm{hCB}_{1}$ and 125-fold greater affinity at $\mathrm{hCB}_{2}$.

Table 1. Methodological Comparison of Five $\Delta^{9}$-Tetrahydrocannabinolic Acid A Affinity Studies

\begin{tabular}{|c|c|c|c|c|}
\hline & Radioligand & CB species & Expression model & THCA-A source \\
\hline Rosenthaler et al. ${ }^{23}$ & {$\left[{ }^{3} \mathrm{H}\right] \mathrm{CP} 55,940$} & $\mathrm{hCB}_{1}$ & Sf9 cells & THC Pharm $\mathrm{GmbH}$, synthetic, $1 \mathrm{mg} / \mathrm{mL}$ in methanol \\
\hline Verhoeckx et al. ${ }^{24}$ & n.d. ${ }^{\mathrm{a}}$ & $\mathrm{hCB}_{1}$ & Sf9 cells & Extracted from plant material, in ethanol \\
\hline Ahmed et al. ${ }^{25}$ & {$\left[{ }^{3} \mathrm{H}\right] \mathrm{CP} 55,940$} & $\mathrm{rCB}_{1}$ & Brain membranes & Extracted from plant material, in hexane \\
\hline Husni et al. ${ }^{26}$ & {$\left[{ }^{3} \mathrm{H}\right] \mathrm{CP} 55,940$} & $\mathrm{rCB}_{1}$ & Brain membranes & Extracted from plant material, in hexane \\
\hline This study & {$\left[{ }^{3} \mathrm{H}\right] \mathrm{CP} 55,940$} & $\mathrm{hCB}_{1}$ & HEK293 cells & Cayman Chemical, synthetic, $1 \mathrm{mg} / \mathrm{mL}$ in acetonitrile \\
\hline
\end{tabular}

${ }^{\mathrm{a} K}$. Verhoeckx (personal communication, April 2017) reports "outsourcing" the affinity part of their study and could not recall the specific radioligand used in the assay.

$\mathrm{hCB}_{1}$, human cannabinoid receptor subtype one; $\mathrm{HEK}$, human embryonic kidney; $\mathrm{rCB}_{1}$, rat cannabinoid receptor subtype one; Sf9, Spodoptera frugiperda clonal isolate 9; THC, $\Delta^{9}$-tetrahydrocannabinol; THCA-A, $\Delta^{9}$-tetrahydrocannabinolic acid $\mathrm{A}$. 
Despite our use of a certified reference standard (meeting ISO17025 guidelines), the reagent nevertheless contained 2\% THC. Numerous web sites advertise "crystalline THCA" and claim 99\% to $100 \%$ purity. These gray market sources pose legal barriers regarding inter- national shipment, lack ISO17025 standards, and await purity authentication. Hypothetically these products contain THCA-B, which crystalizes more readily than THCAA. ${ }^{2}$ THCA-B also demonstrates greater thermal stability than THCA-A, ${ }^{32-34}$ so it may be worth investigating.
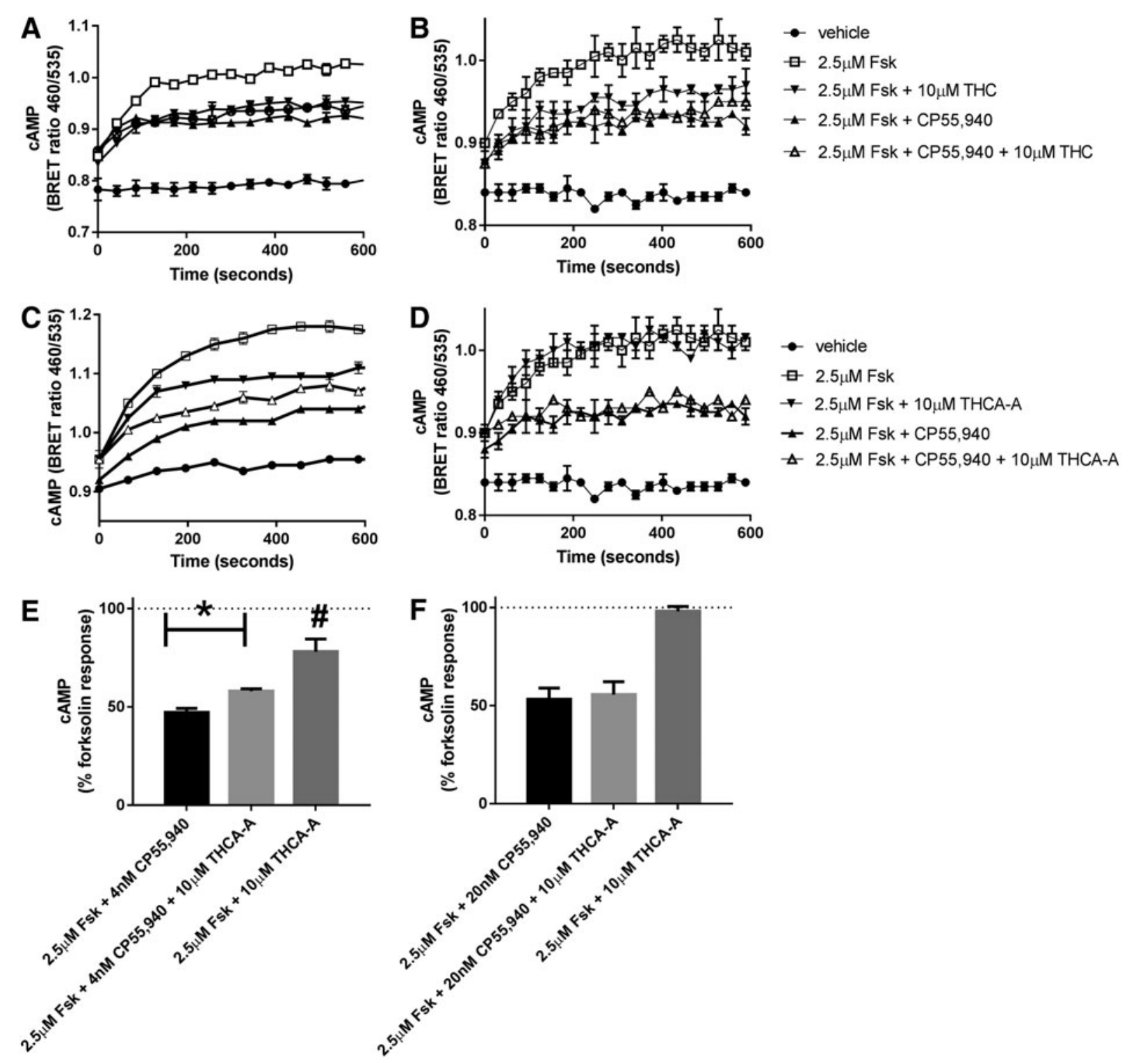

FIG. 4. Efficacy of THCA-A and THC in CAMP assays, $C B_{1}$ on the left, $C B_{2}$ on the right. (A-D) Show representative images of the biosensor traces of single experiments carried out in duplicate. (A, B) Show that THC $(10 \mu \mathrm{M})$ inhibits $C A M P$ at both $\mathrm{CB}_{1}$ (left) and $\mathrm{CB}_{2}$ (right). (C, D) Show the same assay carried out with THCA-A. THCA-A can be seen to inhibit forskolin mediated CAMP alone and to partially antagonize the ability of $C P 55,940$ to inhibit $C A M P$ at $C_{1}$, but has no effect under equivalent conditions at $C_{2}$. The lower panels $(\mathbf{E}, \mathbf{F})$ are summary data for the area under the curve analyses for all replicate assays combined $(n=5$ for $\mathrm{CB}_{1}$ or $n=6$ for $\mathrm{CB}_{2}$ ). ${ }^{*} p=0.0065$ by paired $t$-test, $n=5$. ${ }^{\#} p=0.015 t$-test compared to $100 \%$. cAMP, cyclic adenosine monophosphase. 
However, only two studies have quantified THCA-A and THCA-B content in a variety of Cannabis landraces, ${ }^{33,34}$ so the prevalence of THCA-B is relatively unknown.

Given the susceptibility of THCA-A to lose its carboxylic acid moiety, contamination by THC may be difficult to avoid, as lamented by pharmacologists evaluating THCA-A. ${ }^{21}$ At a concentration of $10 \mu \mathrm{M}$ THCA-A, the reagent contained $\sim 200 \mathrm{nM}$ THC. In our $\mathrm{hCB}_{1}$ competition binding assay, THCA-A displacement at $10 \mu \mathrm{M}$ approximated THC displacement at $200 \mathrm{nM}$ (Fig. 3). We therefore suspect that some of our THCA-A binding curve was artifact-from its inevitable decarboxylation into THC-and the binding affinity of THCA-A at hCB is even weaker than our estimated values.

Consistent with low affinity, THCA-A showed low efficacy at $\mathrm{hCB}_{1}$. THCA-A $(10 \mu \mathrm{M})$ produced a small but significant inhibition of forskolin cAMP, consistent with agonist activity. Due to solubility issues and the low potency of this compound, sufficiently high concentrations to determine the extent of agonism were not possible without reaching unacceptably high levels of solvent. As is consistent with a weak agonist, THCAA slightly antagonized the effect produced by an $\mathrm{EC}_{90}$ concentration of $\mathrm{CP} 55,940$. Regarding $\mathrm{hCB}_{2}$, THCAA produced no significant effect in cAMP assays.

Verhoeckx et al. ${ }^{24}$ also measured efficacy, and their results correlated with ours-THCA-A at $\mathrm{hCB}_{1}$ showed no influence on cAMP production. However, THC showed no efficacy in their hands, either. Husni et al. ${ }^{26}$ used a different efficacy assay: agonist-stimulated $\left[{ }^{35} \mathrm{~S}\right] \mathrm{GTP} \gamma \mathrm{S}$ binding in mouse brain membranes. The $\mathrm{EC}_{50}$ concentration of THC was $269 \mathrm{nM}$, whereas THCA-A was $>10,000 \mathrm{nM}$. Lack of affinity and efficacy of THCA-A at $\mathrm{hCB}_{1}$ seems consistent with in vivo studies, where THCA-A lacked cannabimimetic activity in rodents and primates. ${ }^{15,21,22}$

Many questions regarding THCA-A remain unanswered. For example, an in vivo study of rats and shrews showed that antiemetic effects by THCA-A were blocked by rimonabant. ${ }^{22}$ This suggests a $\mathrm{CB}_{1}$-mediated mechanism, yet the authors reported that THCA-A did not induce $\mathrm{CB}_{1}$ agonist effects such as hypothermia or reduced motor activity. THCA-A is a promiscuous ligand and targets many molecular targets. ${ }^{30}$ However, its clinical usefulness, and its amenity to pharmacological analysis, may be hampered by its instability.

\section{Acknowledgments}

The authors gratefully acknowledge two anonymous reviewers for improving our article and personal com- munications by THCA-A researchers (S. Rosenthaler, K. Verhoeckx, and M. Radwan).

\section{Author Disclosure Statement}

No competing financial interests exist.

\section{References}

1. Mechoulam R, Ben-Zvi Z, Yagnitinsky B, et al. A new tetrahydrocannabinolic acid. Tetrahedron Lett. 1969;10:2339-2341.

2. Rosenqvist $\mathrm{E}$, Ottersen $\mathrm{T}$. The crystal and molecular structure of $\Delta^{9}$ tetrahydrocannabinolic acid B. Acta Chem Scand B. 1975;29:379-384.

3. Russo E. Cannabis and epilepsy: an ancient treatment returns to the fore. Epilepsy Behav. 2016 Dec 15 [Epub ahead of print]

4. Sulak D, Saneto R, Goldstein B. The current status of artisanal cannabis for the treatment of epilepsy in the United States. Epilepsy Behav. 2017 Feb 18 [Epub ahead of print]

5. Romano LL, Hazekamp A. Cannabis oil: chemical evaluation of an upcoming cannabis-based medicine. Cannabinoids. 2013;1:1-11.

6. Citti C, Ciccarella G, Braghiroli D, et al. Medicinal cannabis: principal cannabinoids concentration and their stability evaluated by a high performance liquid chromatography coupled to diode array and quadrupole time of flight mass spectrometry method. J Pharm Biomed Anal. 2016;128:201-209.

7. Peschel W. Quality control of traditional cannabis tinctures: pattern, markers, and stability. Sci Pharm. 2016;84:567-584.

8. Smith RN, Vaughan CG. The decomposition of acidic and neutral cannabinoids in organic solvents. J Pharm Pharmacol. 1977;29:286290.

9. Veress T, Szanto Jl, Leisztner L. Determination of cannabinoid acids by high-performance liquid chromatography of their neutral derivatives formed by thermal decarboxylation: I. Study of the decarboxylation process in open reactors. J Chromatogr A. 1990;520:339-347.

10. Hazekamp A, Bastola K, Rashidi H, et al. Cannabis tea revisited: a systematic evaluation of the cannabinoid composition of cannabis tea. J Ethnopharmacol. 2007;113:85-90.

11. De Zeeuw RA, Malingre TM, Merkus FW. Delta-1-tetrahydrocannabinolic acid, an important component in the evaluation of cannabis products. J Pharm Pharmacol. 1972;24:1-6.

12. Potter $D$. The propagation, characterisation and optimisation of Cannabis sativa L. as a phytopharmaceutical. Doctoral thesis, King's College, London, 2009.

13. Russo EB. Taming THC: potential cannabis synergy and phytocannabinoid-terpenoid entourage effects. Br J Pharmacol. 2011;163:1344-1364.

14. Copolovici LO, Filella I, Llusià J, et al. The capacity for thermal protection of phyotosynthetic electron transport varies for different monoterpenes in Quercus ilex. Plant Physiol. 2005;139:485-496.

15. Yamauchi T, Shoyama Y, Aramaki H, et al. Tetrahydrocannabinolic acid a genuine substance of tetrahydrocannabinol. Chem Pharm Bull (Tokyo). 1967;15:1075-1076.

16. Doorenbos NJ, Fetterman PS, Quimby MW, et al. Cultivation, extraction and analysis of Cannabis sativa L. Ann N Y Acad Sci. 1971;191: 3-14.

17. Turner CE, Hadley KW, Fetterman PS, et al. Constituents of Cannabis sativa L. IV: stability of cannabinoids in stored plant material. J Pharm Sci. 1973;62:1601-1605.

18. Yotoriyama M. The decrease of tetrahydrocannabinolic acid (THCA) in Cannabis leaves during storage. Eisei Kagaku. 1980;26:5053.

19. Lindholst C. Long term stability of cannabis resin and cannabis extracts. Aust J Forensic Sci. 2010;42:181-190.

20. Baker PB, Taylor BJ, Gough TA. The tetrahydrocannabinol and tetrahydrocannabinolic acid content of cannabis products. J Pharm Pharmacol. 1981;33:369-372.

21. Edery $H$, Grunfeld $Y$, Porath $G$, et al. Structure-activity relationships in the tetrahydrocannabinol series. Arzneimittelforschung. 1972;22:19952003.

22. Rock EM, Kopstick RL, Limebeer $\mathrm{CL}$, et al. Tetrahydrocannabinolic acid reduces nausea-induced conditioned gaping in rats and vomiting in Suncus murinus. Br J Pharmacol. 2013;170:641-648. 
23. Rosenthaler S, Pöhn B, Kolmanz C, et al. Differences in receptor binding affinity of several phytocannabinoids do not explain their effects on neural cell cultures. Neurotoxicol Teratol. 2014;46:49-56.

24. Verhoeckx KC, Korthout HA, van Meeteren-Kreikamp AP, et al. Unheated Cannabis sativa extracts and its major compound THC-acid have potential immuno-modulating properties not mediated by $\mathrm{CB}_{1}$ and $\mathrm{CB}_{2}$ receptor coupled pathways. Int Immunopharmacol. 2006;6:656-665.

25. Ahmed SA, Ross SA, Slade D, et al. Cannabinoid ester constituents from high-potency Cannabis sativa. J Nat Prod. 2008;71:536-542.

26. Husni AS, McCurdy CR, Radwan MM, et al. Evaluation of phytocannabinoids from high potency Cannabis sativa using in vitro bioassays to determine structure-activity relationships for cannabinoid receptor 1 and cannabinoid receptor 2. Med Chem Res. 2014;23:4295-4300.

27. Redmond WJ, Cawston EE, Grimsey NL, et al. Identification of Narachidonoyl dopamine as a highly biased ligand at cannabinoid $\mathrm{CB}_{1}$ receptors. Br J Pharmacol. 2016;173:115-127.

28. Cawston EE, Redmond WJ, Breen CM, et al. Real-time characterization of cannabinoid receptor $1\left(\mathrm{CB}_{1}\right)$ allosteric modulators reveals novel mechanism of action. Br J Pharmacol. 2013;170:893-907.

29. Grimsey NL, Goodfellow CE, Dragunow M, et al. Cannabinoid receptor 2 undergoes Rab5-mediated internalization and recycles via a Rab11dependent pathway. Biochim Biophys Acta. 2011;1813:1554-1560.

30. Moreno-Sanz G. Can you pass the acid test? Critical review and novel therapeutic perspectives of $\Delta^{9}$-tetrahydrocannabinolic acid A. Cannabis Cannabinoid Res. 2016;1:124-130.

31. McPartland JM, Glass M, Pertwee RG. Meta-analysis of cannabinoid ligand binding affinity and cannabinoid receptor distribution: interspecies differences. Br J Pharmacol. 2007;152:583-589.

32. Turner CE, Hadley KW, Henry J, et al. Constituents of Cannabis sativa L. VII: use of silyl derivatives in routine analysis. J Pharm Sci. 1974;63: 1872-1876.

33. Brenneisen R, ElSohly MA. Chromatographic and spectroscoic profiles of Cannabis of different origins: part 1. J Forensic Sci. 1988;33:1385-1404.
34. Hanuš LO, Meyer SM, Muñoz E, et al. Phytocannabinoids: a unified critical inventory. Nat Prod Rep. 2016;33:1357.

Cite this article as: McPartland JM, MacDonald C, Young M, Grant PS Furkert DP, Glass M (2017) Affinity and efficacy studies of tetrahydrocannabinolic acid $A$ at cannabinoid receptor types one and two, Cannabis and Cannabinoid Research 2:1, 87-95, DOI: 10.1089/ can.2016.0032

$\begin{aligned} & \text { Abbreviations Used } \\ & \mathrm{BRET}=\text { bioluminescence resonance energy transfer } \\ & \mathrm{BSA}=\text { bovine serum albumin } \\ & \mathrm{CAMP}=\text { cyclic adenosine monophosphase } \\ & \mathrm{CB}=\text { cannabinoid receptor subtype one } \\ & \mathrm{CB}_{2}=\text { cannabinoid receptor subtype two } \\ & \mathrm{h}=\text { human } \\ & \mathrm{HBSS}=\text { Hank's balanced salt solution } \\ & \mathrm{HEK} 293=\text { human embryonic kidney cell line } 293 \\ & \mathrm{HPLC}=\text { high performance liquid chromatography } \\ & \mathrm{IC} \mathrm{C}_{50}=\text { half maximal inhibitory concentration } \\ & \mathrm{K}_{\mathrm{i}}=\text { dissociation constant in a competition binding assay } \\ & \mathrm{PBS}=\text { phosphate buffered saline } \\ & \mathrm{THC}=\Delta^{9} \text {-tetrahydrocannabinol } \\ & \mathrm{THCA}-\mathrm{A}=\Delta^{9} \text {-tetrahydrocannabinolic acid A } \\ & \mathrm{THCA}-\mathrm{B}=4 \text {-COOH-THC }\end{aligned}$

Cannabis and Cannabinoid Research
- Immediate, unrestricted online access

- Rigorous peer review

- Compliance with open access mandates

- Authors retain copyright

- Highly indexed

- Targeted email marketing 